\title{
Biscoitos tipo cookie sem glúten enriquecido com farinha de resíduos de laranja
}

\author{
Gluten-free cookies enriched with orange residue flour \\ Galletas sin gluten enriquecidas con harina de residuo de naranja
}

Recebido: 03/08/2021 | Revisado: 13/08/2021 | Aceito: 20/08/2021 | Publicado: 22/08/2021

\author{
Matheus dos Santos Miranda \\ ORCID: https://orcid.org/0000-0002-5549-017X \\ Universidade Federal do Maranhão, Brasil \\ E-mail: matheus_s_miranda@hotmail.com \\ Vinícius Costa Barros \\ ORCID: https://orcid.org/0000-0002-3339-5040 \\ Universidade Federal do Maranhão, Brasil \\ E-mail: vi_costa_b@outlook.com \\ Virlane Kelly Lima Hunaldo \\ ORCID: https://orcid.org/0000-0002-5827-2987 \\ Universidade Federal do Maranhão, Brasil \\ Email: virlanekelly@yahoo.com.br \\ Leonardo Hunaldo dos Santos \\ ORCID: https://orcid.org/0000-0003-2280-4643 \\ Universidade Federal do Maranhão, Brasil \\ E-mail: leohunaldo@gmail.com \\ Adriana Crispim de Freitas \\ ORCID: https://orcid.org/0000-0001-6310-0015 \\ Universidade Federal do Maranhão, Brasil \\ E-mail: adriana.crispim@ufma.br \\ Jaisane Santos de Melo Lobato \\ ORCID: https://orcid.org/0000-0002-3610-7753 \\ Universidade Federal do Pará, Brasil \\ E-mail: jaisanelobato@hotmail.com \\ Maria Alves Fontenele \\ ORCID: https://orcid.org/0000-0003-0780-7563 \\ Universidade Federal do Maranhão, Brasil \\ E-mail: maria.fontenele@ufma.br
}

\begin{abstract}
Resumo
Esse estudo teve como objetivo desenvolver biscoitos tipo cookies a partir da utilização de farinha de resíduo de laranja como substituição parcial da farinha de arroz (FRL0\%, FRL10\%, FRL20\%). Foram realizadas análises microbiológicas, físico-químicas ( $\mathrm{pH}$, aW e cor instrumental) e análise sensorial por meio da escala hedônica, atitude de compra e escala do ideal avaliando o sabor, crocância e sabor residual. As análises microbiológicas indicaram ausência para coliformes a $45^{\circ} \mathrm{C}$, bactérias aeróbias mesófilas e Salmonella $\mathrm{sp}$. Em relação aos resultados de cor instrumental não houve diferença significativa no parâmetro $b^{*}$ para as três amostras, no entanto houve diferença significativa para as intensidades de $\mathrm{L}^{*}$ e $\mathrm{a}^{*}$. Os resultados de aW das amostras testadas não diferiram significativamente entre si, porém, o pH apresentou redução de acordo com o aumento do teor de farinha de resíduo de laranja. Quanto a análise sensorial, não foram observadas diferenças significativas $(\mathrm{p}<0,05)$ para os atributos cor, aroma, textura, acidez e impressão global entre as amostras contendo 10 e $0 \%$ de farinha de resíduo de laranja. Observou-se que a crocância e sabor residual das amostras com FRL10\% e FRL0\% se apresentaram semelhantes e ideais de acordo com o teste, isso implica que a substituição de FRL10\% foi bastante satisfatória e com características sensoriais semelhantes à de biscoitos formulados com farinha de arroz. Portanto, a farinha de resíduo de laranja é uma alternativa viável para a produção de biscoitos tipo cookie, sabendo-se que este trata-se de um resíduo pouco utilizado produção de biscoitos.
\end{abstract}

Palavras-chave: Biscoitos; Cookies; Farinha de resíduo de laranja.

\section{Abstract}

This study aimed to develop cookie-type cookies from the use of orange residue flour as a partial replacement for rice flour (ORF0\%, ORF10\%, ORF20\%). Microbiological, physicochemical analyzes (pH, aW and instrumental color) and sensory analysis were performed using the hedonic scale, purchase attitude and ideal scale, evaluating flavor, crispness and aftertaste. Microbiological analyzes indicated absence for coliforms at $45^{\circ} \mathrm{C}$, mesophilic aerobic bacteria and Salmonella sp. Regarding the results of instrumental color, there was no significant difference in the parameter $b^{*}$ for the three samples, however there was a significant difference for the intensities of $\mathrm{L}^{*}$ and $\mathrm{a}^{*}$. The aW results of the tested samples did not differ significantly from each other, however, the $\mathrm{pH}$ showed a reduction according to the increase 
in the orange residue flour content. As for the sensory analysis, no significant differences were observed $(p<0.05)$ for the attributes color, aroma, texture, acidity and global impression between samples containing 10 and $0 \%$ of orange residue flour. It was observed that the crispness and aftertaste of the samples with ORF10\% and ORF0\% were similar and ideal according to the test, which implies that the replacement of ORF10\% was quite satisfactory and with sensory characteristics like those of cookies made with flour of rice. Therefore, the orange residue flour is a viable alternative to produce this model of cookies, knowing that this is a little used residue to produce cookies.

Keywords: Biscuits; Cookies; Orange residue flour.

\section{Resumen}

Este estudio tuvo como objetivo desarrollar galletas tipo cookie a partir del uso de harina de residuo de naranja como reemplazo parcial de la harina de arroz (HRN0\%, HRN10\%, HNR20\%). Se realizaron análisis microbiológicos, fisicoquímicos $(\mathrm{pH}, \mathrm{aW}$ y color instrumental) y análisis sensorial utilizando la escala hedónica, actitud de compra y escala ideal, evaluando sabor, frescura y regusto. Los análisis microbiológicos indicaron ausencia de coliformes a $45^{\circ}$ C, bacterias aerobias mesófilas y Salmonella sp. En cuanto a los resultados del color instrumental, no hubo diferencia significativa en el parámetro $\mathrm{b} *$ para las tres muestras, sin embargo sí hubo diferencia significativa para las intensidades de L* y a *. Los resultados aW de las muestras analizadas no difirieron significativamente entre sí, sin embargo, el pH mostró una reducción de acuerdo con el aumento en el contenido de harina de residuo de naranja. En cuanto al análisis sensorial, no se observaron diferencias significativas $(\mathrm{p}<0.05)$ para los atributos color, aroma, textura, acidez e impresión global entre muestras que contenían 10 y $0 \%$ de residuo de harina de naranja. Se observó que el crujiente y regusto de las muestras con HNR10\% y HNR0\% fueron similares e ideales según la prueba, lo que implica que la reposición de HNR10\% fue bastante satisfactoria y con características sensoriales similares a las de las galletas elaboradas con harina de arroz. Por tanto, la harina de residuo de naranja es una alternativa viable para la producción de galletas tipo cookie, sabiendo que se trata de un residuo poco utilizado para la producción de galletas.

Palabras clave: Cookies; Galletas; Harina de residuos de naranja.

\section{Introdução}

O Brasil se destaca como o maior produtor mundial de laranjas sendo responsável por 50\% da produção mundial de suco, alcançando dessa forma 85\% da participação no mercado mundial (Agrinual, 2016). Em 2019 a produção nacional foi de 17.073.593 toneladas, com média de $28.957 \mathrm{~kg}$ por hectare (IBGE, 2021).

Grande parte do que é produzido é transformado em suco, o que no Brasil corresponde a 96\% da produção nacional, gerando uma elevada quantidade de resíduos, que equivalem a 50\% do peso da fruta (Cayres, 2014). Os resíduos gerados no processamento de cítricos são importante fonte de flavonóides naturais e contém uma expressiva concentração de compostos fenólicos (Rosolem, 2018).

Uma boa alternativa para aproveitar os resíduos provenientes das frutas, e que já vem sendo desempenhada por vários estudiosos ao longo do tempo, é o desenvolvimento de novos alimentos que os utilizassem, como a produção de bolos, barras de cereais e biscoitos, elaborados a partir da farinha desses subprodutos (De Sá Leitão \& De Sá Leitão, 2015).

Como exemplo no desenvolvimento tecnológico da cadeia de produção alimentícia, temos a produção de farinhas para incorporação parcial ou total em alimentos como, pães, bolos, cookies, biscoitos, bolachas, mingaus e sopas, cujo benefício está na prevenção de desperdícios, incorporação de nutrientes que existem nos resíduos além de outros fatores benéficos (Farias Silva et al., 2016; Bender et al., 2016)

Segundo a Agência Nacional de Vigilância Sanitária - ANVISA (Brasil, 2005) as farinhas são produtos contraídos de partes comestíveis de uma ou mais espécies de cereais, leguminosa, frutas, sementes, tubérculos e rizomas por trituração e/ou outros métodos tecnológicos visto como bons para a produção de alimentos.

A resolução RDC n 263 da Agência Nacional de Vigilância Sanitária define biscoito ou bolacha como os produtos obtidos pela mistura de farinha(s), amido(s) ou fécula(s) com outros ingredientes, submetidos a processos de amassamento e cocção, fermentados ou não. Podem apresentar cobertura, recheio, formato e textura diversos (Brasil, 2005). De acordo com Pareyt et al. (2009) os cookies são produtos assados com adição de cereais, altos níveis de açúcar e de gordura além de baixos níveis de água (1-5\%). 
Atualmente o Brasil é o $3^{\circ}$ maior produtor de biscoitos do mundo e produziu em 2020, 1.530 milhões de toneladas (Abimapi, 2021). Sua qualidade está relacionada com o sabor, a textura, a aparência entre outros fatores, e nos últimos anos vem se destacando como um produto de grande interesse comercial em decorrência de sua praticidade na produção, comercialização e consumo, além de possuir longa vida comercial (Santos, 2011). Os biscoitos cookie são ricos em valor nutricional e fibras devido a diversidade desses nutrientes e por serem encontrados facilmente em talos, folhas e raízes que seriam descartados logo após etapas de seleção e corte, além das demais frutas e vegetais que caracterizam esses nutrientes e fibras alimentares como de origem natural (Fasolin et al., 2007; Moraes et al., 2010; Calleguari et al., 2010). As fibras alimentares desenvolvem papéis importantes no trato gastrintestinal humano promovendo assim, a regulação no tempo de trânsito intestinal e apresentam também alto poder de saciedade (Lima et al., 2006).

De acordo com Matos (2016), a doença celíaca caracteriza-se pela não absorção permanente ao glúten pelo organismo, uma proteína encontrada em cereais como trigo, cevada, centeio, malte e aveia. Apresenta-se como uma desordem imunomediada do intestino delgado, desencadeada pela sensibilização contínua do sistema imune contra os peptídeos do glúten em indivíduos geneticamente favoráveis a condição. A doença celíaca envolve além de fatores genéticos, envolve fatores ambientais e imunológicos, ou seja, é uma desordem multifatorial de manifestações clínicas diversas (Matos, 2016).

A adoção de uma dieta totalmente isenta de glúten não constitui uma prática fácil. A problemática da insegurança alimentar e nutricional enfrentada pelo indivíduo celíaco está na dificuldade, no acesso e na disponibilidade de produtos sem glúten, em razão da pequena oferta, alto custo e inacessíveis às classes sociais menos favorecidas. (Mariani, 2015).

Diversos estudos vêm sendo realizados com a substituição de parte da farinha de trigo por outras fontes de fibras ou proteínas, visando o desenvolvimento de novos produtos. Entre eles destacam-se a adição de fécula de mandioca, polvilho azedo e albedo de laranja (Santos et al., 2011), farinha de aveia e farinha de arroz parboilizado (Assis et al., 2009) e farinha de amaranto (Capriles et al., 2006). O'Shea et al. (2015) utilizou a farinha do bagaço da laranja, elaborada a partir da casca, polpa e sementes que ficaram após a retirada do suco, como ingrediente para produção de um pão sem glúten encontrando um produto viável nutricional e economicamente.

Esse estudo teve como objetivo desenvolver biscoitos tipo cookies sem glúten a partir da utilização de farinha de resíduo de laranja como substituição parcial da farinha de arroz.

\section{Material e Métodos}

Para a elaboração da farinha de resíduo de laranja (FRL), foram utilizados os resíduos da produção de suco de laranja no Laboratório de Tecnologia de Vegetais da Universidade Federal do Maranhão - Campus Avançado. Foram selecionados o albedo (mesocarpo) e o bagaço (membrana carpelar e vesícula de suco) de acordo com a viabilidade de aproveitamento dos resíduos, descartando os que apresentavam senescência elevada ou injúria, em seguida foram acomodadas em bandejas e submetidos a secagem em estufa de circulação e renovação forçada de ar (Modelo SL-102, SOLAB), a $65^{\circ} \mathrm{C}$ por 24 horas, posteriormente triturado em moinho de facas. Por fim, a farinha que apresentou de $1 \mu \mathrm{m}$ até $50 \mu \mathrm{m}$ de diâmetro foi novamente levada a estufa por 1 hora a $90^{\circ} \mathrm{C}$ para controle microbiológico.

Os demais ingredientes como, farinha de arroz (pó), açúcar mascavo, margarina, ovo, linhaça, essência de baunilha e bicarbonato de sódio foram adquiridas no comércio local.

Foram elaboradas três formulações baseadas em uma receita convencional americana de biscoito tipo cookie, a amostra controle contendo 0\% de FRL, uma contendo 10\% de FRL e uma com 25\% de FRL substituindo parcialmente a farinha de arroz. Para a elaboração dos biscoitos cookies foram utilizados os ingredientes conforme a Tabela 1. 
Tabela 1. Proporções dos ingredientes utilizados para elaboração do biscoito cookie FRL0\%, FRL10\% e FRL25\% em substituição a farinha de arroz, intervalos escolhidos devido a conferência de padrão de identidade e qualidade de cookies. Em relação ao percentual total de farinha a FRL10\% representa 9,5\% da farinha total do cookie e a FRL25\% representa $27 \%$ da farinha total.

\begin{tabular}{|c|c|c|c|}
\hline Ingredientes (g) & FRLO\% & FLR10\% & FRL25\% \\
\hline$\overline{\text { FRL }}$ & 0 & 10 & 25 \\
\hline Farinha de Arroz & 100 & 90 & 75 \\
\hline Açúcar mascavo & 59 & 59 & 59 \\
\hline Margarina & 59 & 59 & 59 \\
\hline Ovo & 35 & 35 & 35 \\
\hline Farinha de Linhaça & 15 & 15 & 15 \\
\hline Essência de baunilha & 2 & 2 & 2 \\
\hline Bicarbonato de sódio & 1 & 1 & 1 \\
\hline
\end{tabular}

Fonte: Autores (2021).

No preparo da massa, iniciou-se com a pesagem dos ingredientes e em seguida misturou-se o açúcar mascavo, margarina, ovo, essência de baunilha e o bicarbonato em batedeira planetária da marca Arno por dois minutos em velocidade baixa até a formação de um creme. Posteriormente, foram adicionados os demais ingredientes, farinha de arroz e FRL de acordo com cada formulação, foram misturados por três minutos em velocidade média até a obtenção de uma massa homogênea. Por fim a massa foi deixada em repouso por 10 minutos. Após essa etapa a massa foi cortada e pesadas a fim de padronizar com peso médio de $8 \mathrm{~g}$ e em seguida foram moldadas e colocadas em formas previamente forradas com papel manteiga. O assamento foi conduzido a $180-200{ }^{\circ} \mathrm{C}$ durante 15 minutos em forno industrial pré-aquecido. Após o assamento, os biscoitos foram retirados e resfriados em temperatura ambiente e armazenados em potes de plástico até o momento das análises.

\subsection{Análises}

\subsubsection{Análises Microbiológicas}

As análises microbiológicas foram realizadas em triplicata, seguindo a metodologia proposta pela American Public Health Association, que determina o número mais provável (NMP) de coliformes a $45^{\circ} \mathrm{C} \mathrm{g}^{-1}$, bactérias aeróbias mesófilas e Salmonella sp. (APHA, 2015).

\subsubsection{Análises Físico-Químicas}

Os biscoitos foram avaliados quanto a atividade de água (aW) usando o equipamento Medidor de atividade de água (AQUALAB® - Modelo 4TE) e o pH foi determinado em pHmetro de bancada EHC segundo método descrito pelo Instituto Adolfo Lutz (2008), em triplicata, depois de prontos (pós-cocção). A cor instrumental dos biscoitos foi medida pelo espectrofotômetro (Minolta, CM 2300D, Tokyo, Japão), operando no sistema CIE (L*, a* e b*). Sendo L* a luminosidade, variando de 0 (preto) para 100 (branco), $a^{*}$ a intensidade da cor vermelha que varia de verde (-60) a vermelho (+60) e $b^{*} a$ intensidade de cor que varia de azul (-60) a amarelo (+60). A calibração do aparelho foi realizada por meio de placa de cerâmica branca, utilizando-se o iluminante $\mathrm{D}_{65}$. 


\subsubsection{Análise Sensorial}

O projeto foi submetido ao Comitê de Ética em Pesquisa sendo aprovado sob o número do CAAE 30538720.9.0000.5087.

O teste sensorial foi realizado no Laboratório de Análise Sensorial da Universidade Federal do Maranhão com 80 provadores não treinados de ambos os sexos, utilizando-se cabines individuais sob a incidência de iluminação artificial do tipo luz branca. Cada provador recebeu três amostras de biscoito de aproximadamente $8 \mathrm{~g}$ cada, e um copo com aproximadamente $200 \mathrm{ml}$ de água. As amostras foram servidas em ordem sequencial monádica, em guardanapos codificados com números de três dígitos aleatórios.

Primeiramente, avaliou-se a aceitação sensorial das formulações utilizando escala hedônica estruturada mista de nove pontos $(9$ = gostei muitíssimo, 8 = gostei muito, 7 = gostei moderadamente, $6=$ gostei ligeiramente, 5 = não gostei; nem desgostei; 4 = desgostei ligeiramente, 3 = desgostei moderadamente, 2 - desgostei muito 1 = desgostei muitíssimo), para os atributos: cor, acidez, aroma, sabor e textura e impressão global”. (Dutcosky, 2013, Minim, 2013). A escala do ideal para os termos sabor, crocância e sabor do resíduo, de nove pontos, também foi aplicada $(+4=$ extremamente mais forte que o ideal; $+3=$ muito mais forte que o ideal $;+2=$ moderadamente mais forte que o ideal $;+1=$ Ligeiramente mais forte que o ideal $; 0=$ ideal $;-1=$ ligeiramente menos forte que o ideal; $-2=$ moderadamente menos forte que o ideal; $-3=$ muito menos forte que $\mathrm{o}$ ideal; $-4=$ extremamente menos forte que o ideal) (Dutcoscky, 2013, Minim, 2013).

No mesmo formulário de avaliação, entregue ao julgador, a intenção de compra do produto baseou-se na impressão geral dos consumidores, sendo avaliada mediante escala de atitude de compra estruturada mista de cinco pontos, tendo como extremos "certamente não compraria" e "certamente compraria" (Dutcosky, 2013; Minim, 2013).

\subsubsection{Análise Estatística}

Foi considerado um experimento em delineamento inteiramente casualizado, com as formulações de biscoitos contendo variações FRL0\%, FRL10\% e FRL25\%, sendo que as variáveis físico-químicas avaliadas foram: L, a, b, pH e aW. Testes de normalidade de Shapiro-Wilk e testes de homogeneidade de variância de Bartlett, ambos a 5\% de significância ( $p>0,05)$, foram realizados para verificar a possibilidade de realizar Análise de Variância (ANOVA).

Os biscoitos com teor FRL0\% (tratamento 1), FRL10\% (tratamento 2), FRL25\% (tratamento 3), os provadores (blocos), e os atributos; cor, aroma, sabor, textura, acidez, impressão global, atitude de compra e idealidade para sabor, crocância e sabor residual foram as variáveis usadas no estudo. Por se tratar de variáveis quantitativas discretas, utilizou-se o teste não paramétrico de Friedman (mais de duas amostras dependentes), onde não há suposições sobre a distribuição dos dados, como descrito em Gibbons e Chakraborti (2010). As variáveis significativamente diferentes entre as amostras seguiram para o teste de Dunn.

Utilizou-se ainda, Testes de Postos Sinalizados de Wilcoxon para comparar as medianas da escala do ideal (sabor, crocância e sabor residual) em relação ao valor de referência (zero). Todos os dados foram tabulados e os testes realizados no software IBM SPSS 24 (IBM SPSS Statistics, 2016) a 5\% de significância.

\section{Resultados e Discussões}

As amostras atenderam os requisitos previstos na legislação vigente, ou seja, houve o cumprimento aos padrões exigidos pelo Regulamento Técnico sobre Padrões Microbiológicos para alimentos, conforme estabelecidos na RDC n ${ }^{\circ} 12$ de 02/01/01 (Brasil, 2001), ausência para coliformes a $45^{\circ} \mathrm{C}$, bactérias aeróbias mesófilas e Salmonella sp. Desta forma, foi confirmado a aptidão dos biscoitos ao consumo, uma vez que os mesmos se mostraram estar dentro dos padrões estipulados pela legislação vigente, aprovando a seguridade e a boa manipulação dos alimentos e insumos no processamento do produto final. 
Os resultados das análises físico-químicas dos biscoitos estão apresentados na Tabela 2 para as diferentes concentrações de FRL, sendo que para cada amostra analisada o processo foi realizado em triplicata.

Tabela 2. Valores médios e desvios padrão das características físico-químicas dos biscoitos tipo cookie contendo FRL.

\begin{tabular}{|c|c|c|c|c|c|c|c|}
\hline \multirow[b]{3}{*}{ Parâmetro } & \multicolumn{7}{|c|}{ AMOSTRAS } \\
\hline & \multicolumn{2}{|c|}{ FRL0\% } & \multicolumn{2}{|c|}{ FRL10\% } & \multicolumn{2}{|c|}{ FRL25\% } & \multirow{2}{*}{$-p$-valor $* *$} \\
\hline & Média & DP & Média & DP & Média & DP & \\
\hline$\overline{\mathbf{L} *}$ & $38,94^{\mathrm{a}}$ & 0,48 & $33,42^{b}$ & 0,49 & $34,89^{b}$ & 2,59 & 0,01 \\
\hline$a^{*}$ & $12,32^{\mathrm{b}}$ & 0,39 & $13,25^{\mathrm{ab}}$ & 0,44 & $14,00^{\mathrm{a}}$ & 0,68 & 0,02 \\
\hline $\mathbf{b}^{*}$ & 22,55 & 1,06 & 18,36 & 0,75 & 19,39 & 2,87 & 0,07 \\
\hline pH & $7,04^{\mathrm{a}}$ & 0,18 & $6,14^{\mathrm{b}}$ & 0,12 & $5,84^{\mathrm{b}}$ & 0,13 & $<0,001$ \\
\hline $\mathbf{a W}$ & 0,43 & 0,07 & 0,39 & 0,04 & 0,39 & 0,06 & 0,66 \\
\hline
\end{tabular}

Letras iguais na mesma linha não possuem diferença significativa pelo teste de Tukey ( $p$ > 0,05). Em que: $\mathrm{L}^{*}$ - Luminosidade, $\mathrm{a}^{*}$ - Coordenada vermelho/verde, $\mathrm{b}^{*}$ - Coordenada amarelo/azul, $\mathrm{pH}$ - Potencial Hidrogeniônico e aW - Atividade de Água Fonte: Autores (2021).

Conforme os resultados das análises estatísticas, os parâmetros de cor na coordenada b* não diferiram significativamente $(\mathrm{p}>0,05)$ nas três amostras, já em relação ao atributo Luminosidade foi percebida diferenças significativas da FRL10\% e FRL25\% em referência a FRL0\%, em relação a intensidade da cor vermelha (coordenada a*) também se nota diferença significativa devido FRL0\% e FRL25\% diferirem entre si, para pH as amostras FRL10\% e FRL25\% não diferiram entre si porém são estatisticamente diferentes da amostra FRL0\%, sendo justificado pela incorporação de componentes ácidos proveniente dos resíduos da laranja, quanto maior a proporção, mais ácido poderá ser a farinha diferindo da proporção 0 \% que está na faixa neutra de pH, por fim as amostras FRL0\%, FRL10\% e FRL25\% não se diferem entre si significantemente a 5\% em relação a atividade de água $(\mathrm{aW})$.

Em relação à análise de cor, as amostras apresentaram consideráveis diferenças em relação à luminosidade, descrita por L*. As amostras com FRL10\% e FRL25\% diferiram da amostra controle com 0\% de FRL, indicando que a farinha de resíduo afeta a coloração dos biscoitos deixando o produto mais escuro. Moura et al. (2010) e Germani (2007) também notaram redução da luminosidade em biscoitos conforme se elevou o percentual de substituição de farinha de sementes de abóbora e farinha de berinjela, respectivamente.

Foi notado diferença significativa também para os parâmetros de cor $\mathrm{a}^{*} \mathrm{e} \mathrm{b}^{*}$, que são responsáveis pela cromaticidade (a*: verde-vermelho; $b^{*}$ : azul-amarelo). As formulações com 10 e $25 \%$ de FRL novamente diferiram da amostra controle, de forma que o aumento do percentual de farinha de resíduo de laranja fez com que as amostras tendessem a uma coloração mais vermelha e amarelada comparada às amostras com $0 \%$ de FRL.

Em relação ao pH, foi observado que não houve diferença significativa $(\mathrm{p}<0,05)$ entre os biscoitos com adição de FRL, no entanto houve diferença significativa $(\mathrm{p}<0,05)$ entre as amostras com FRL e controle com médias de 6,14 (10\%), 5,84 (25\%) e 7,04 (0\%) respectivamente. Assim, essa diminuição do pH pode ser explicada pelo aumento do percentual de FRL nas amostras. Resultado semelhante foi observado por Santos et al., (2017) ao analisarem biscoitos salgados enriquecidos com farinha de resíduos de cenouras, os autores observaram que o $\mathrm{pH}$ dos biscoitos diminuíram gradativamente conforme aumento do percentual de farinha de resíduos. 
Nos resultados para atividade de água dos biscoitos tipo cookies, notou-se que estes podem ser classificados como um produto estável do ponto de vista microbiológico, visto que o menor valor de aW para uma amostra foi de 0,38 e o maior valor foi de 0,42. Tais resultados são satisfatórios, pois de acordo com Fennema (2000), valores de atividade de água acima de 0,80 propiciam o desenvolvimento de bolores e leveduras. Klein (2015) obteve resultados semelhantes ao avaliar as características físico-químicas de biscoitos comerciais do tipo cookies, onde a atividade de água dos biscoitos avaliados variou de 0,30 a 0,45. Gomes e Oliveira, (2011) afirmam que quanto menor a atividade de água, maior o tempo de conservação de um alimento, sendo assim, os valores encontrados para os cookies desse construto caracterizam como um produto de armazenamento estável e com uma vida de prateleira adequada para esse tipo de alimento.

Quanto aos atributos sensoriais avaliados, os resultados dos testes de aceitação dos biscoitos estão demonstrados na Tabela 3.

Tabela 3. Valores médios e desvios padrão dos atributos referentes à análise sensorial e atitude de compra dos biscoitos com diferentes formulações de farinha de resíduo de laranja.

\begin{tabular}{|c|c|c|c|c|c|c|c|}
\hline \multirow{3}{*}{ Atributo } & \multicolumn{7}{|c|}{ AMOSTRAS } \\
\hline & \multicolumn{2}{|c|}{ FRL0\% } & \multicolumn{2}{|c|}{ FRL10\% } & \multicolumn{2}{|c|}{ FRL25\% } & \multirow[t]{2}{*}{$p$-valor** } \\
\hline & Média & DP & Média & DP & Média & DP & \\
\hline Cor & $8,02^{\mathrm{a}}$ & 1,00 & $7,75^{\mathrm{ab}}$ & 1,30 & $7,42^{\mathrm{b}}$ & 1,34 & 0,02 \\
\hline Aroma & $7,83^{\mathrm{a}}$ & 1,01 & $7,48^{\mathrm{a}}$ & 1,24 & $6,92^{\mathrm{b}}$ & 1,55 & $<0,001$ \\
\hline Sabor & $7,92^{\mathrm{a}}$ & 1,38 & $7,35^{\mathrm{b}}$ & 1,61 & $5,40^{\mathrm{c}}$ & 2,10 & $<0,001$ \\
\hline Textura & $7,82^{\mathrm{a}}$ & 1,43 & $7,38^{\mathrm{a}}$ & 1,70 & $6,50^{\mathrm{b}}$ & 1,94 & $<0,001$ \\
\hline Acidez & $7,68^{\mathrm{a}}$ & 1,47 & $7,33^{\mathrm{a}}$ & 1,70 & $5,90^{\mathrm{b}}$ & 2,32 & $<0,001$ \\
\hline Impressão global & $7,97^{\mathrm{a}}$ & 1,16 & $7,42^{\mathrm{a}}$ & 1,61 & $6,05^{\mathrm{b}}$ & 1,83 & $<0,001$ \\
\hline Atitude de compra* & $4,18^{\mathrm{a}}$ & 0,97 & $3,82^{\mathrm{b}}$ & 1,05 & $2,40^{\mathrm{c}}$ & 1,08 & $<0,001$ \\
\hline
\end{tabular}

(Cor, Aroma, Sabor, Textura, Acidez e Impressão global) *Escala de 1 a 9. DP - Desvio-padrão. **Teste de Friedman (Médias com letras distintas na mesma linha diferem estatisticamente a 5\% pelo teste de comparação de Dunn). Fonte: Autores (2021).

Os resultados da análise estatística revelaram que não foram encontradas diferenças significativas nos atributos cor, aroma, textura, acidez e impressão global das amostras FRL10\% e a amostra FRL0\%, enquanto para a formulação FRL25\% observou-se diferença significativa para todos os atributos sensoriais avaliados quando comparados com a formulação controle. O sabor e atitude de compra diferiram estatisticamente entre si para as três formulações avaliadas, tais resultados revelam que a população não está acostumada com consumo de cookies com sabor mais ácido e principalmente proveniente de resíduos de acordo com a análise sensorial realizada, sendo necessária estudos com população que tenha preferência afetiva por esse produto e verificar em seu processamento a adição de componentes para ampliação do aceite em populações não acostumadas com o produto.

Observou-se diferença significativa na avaliação de coordenadas de cor a* e na luminosidade dos biscoitos, onde verificou-se que as formulações contendo FRL tiveram cores mais escuras, porém essa diferença não foi relevada por parte dos participantes da análise sensorial, uma vez que não foi fator de interferência na afetividade dos atributos de cada amostra, os biscoitos FRL10\% já não diferiram da amostra controle, a diferença colorimétrica da amostra FRL25\% não foi apontada. Segundo Komeroski (2016), a aparência representa uma das primeiras características que irá refletir imediatamente ao 
julgamento e opinião do consumidor sobre um produto; como os julgadores não perceberam a diferença no atributo colorimétrico, nota-se que esse é um fator estável do produto elaborado.

$\mathrm{Na}$ análise estatística dos resultados para os parâmetros de cor, aroma, textura, acidez e impressão global, as amostras FRL10\% tiveram valores próximos das amostras sem farinha de resíduos de laranja, não diferindo estatisticamente entre si, o que demonstra que mesmo adicionado de farinha de resíduo de laranja, os biscoitos ainda preservam características sensorialmente agradáveis semelhantes a biscoitos sem FRL. Entretanto, para os atributos sabor e atitude de compra, foi encontrado diferença significativa entre as amostras com diferentes concentrações de FRL em comparação a amostra controle. Os atributos aroma, textura, acidez e impressão global, tiveram diferença somente para as amostras com percentual de substituição da farinha de arroz por FRL25\% sendo essa formulação a menos aceita pelos avaliadores e diferente significativamente $(\mathrm{p}<0,05)$ pela análise estatística.

Conforme os resultados da análise sensorial e atitude de compra na Tabela 3, foi verificado boa aceitação para as amostras com 10\% de farinha de resíduo de laranja, tendo em vista que a média de cada produto avaliado foi superior a 7 , diferindo significativamente $(\mathrm{p}<0,05)$ da amostra controle (FRL0\%) apenas nos parâmetros de sabor e atitude de compra.

Esses resultados mostram que mesmo os biscoitos sem farinha de resíduo de laranja sendo os mais aceitos, as amostras com substituição parcial de $10 \%$ da farinha de arroz por FRL têm avaliação significativamente boa, sendo sim, considerável a produção de cookies com substituição parcial de FRL. Com base nas médias da análise sensorial para os atributos de aroma, sabor, textura, acidez e impressão global, Silva (2019) obteve resultados inferiores ao avaliar a aceitação de farinha de caroço de abacate em cookies, no qual foi verificado que a média hedônica para os atributos de aparência, cor, e textura foram de 4,6 ("desgostei ligeiramente"). No entanto, quando comparado aos resultados de Erkel (2015) os resultados foram similares ao avaliar cookies com utilização da farinha de casca de abacaxi (FCA): entre crianças, visto que as amostras com teor de FCA menor que 10\% apresentaram maior aceitação nos atributos aroma, sabor, cor, aceitação global e intenção de compra.

Tabela 4. Comparação da mediana da escala do ideal em relação ao valor de referência (mediana de referência é zero, que indica o "ideal")

\begin{tabular}{lccc}
\hline & FRL0\% & FRL10\% & FRL25\% \\
\hline Escala do ideal & $p$-valor & $p$-valor & $p$-valor \\
\hline Sabor & 0,19 & 0,45 & $<0,001$ \\
Crocância & 0,42 & 0,07 & 0,03 \\
Sabor residual & 0,07 & 0,40 & $<0,001$ \\
\hline
\end{tabular}

*Teste de Postos Sinalizados de Wilcoxon para comparar as medianas ao valor de referência (zero). Fonte: Autores (2021).

Da Tabela 4 é possível avaliar que a formulação FRL25\% é julgada como ideal em sabor, crocância e sabor residual por parte dos participantes mesmo sendo o produto com menor aceitação sensorial afetiva, mostrando assim que a formulação da FRL25\% pode ser melhorada assim como seus processos para o aumento da aceitação hedônica desse biscoito tipo cookie. 
Figura 1. Escala do ideal para o sabor de acordo como tipo de biscoito

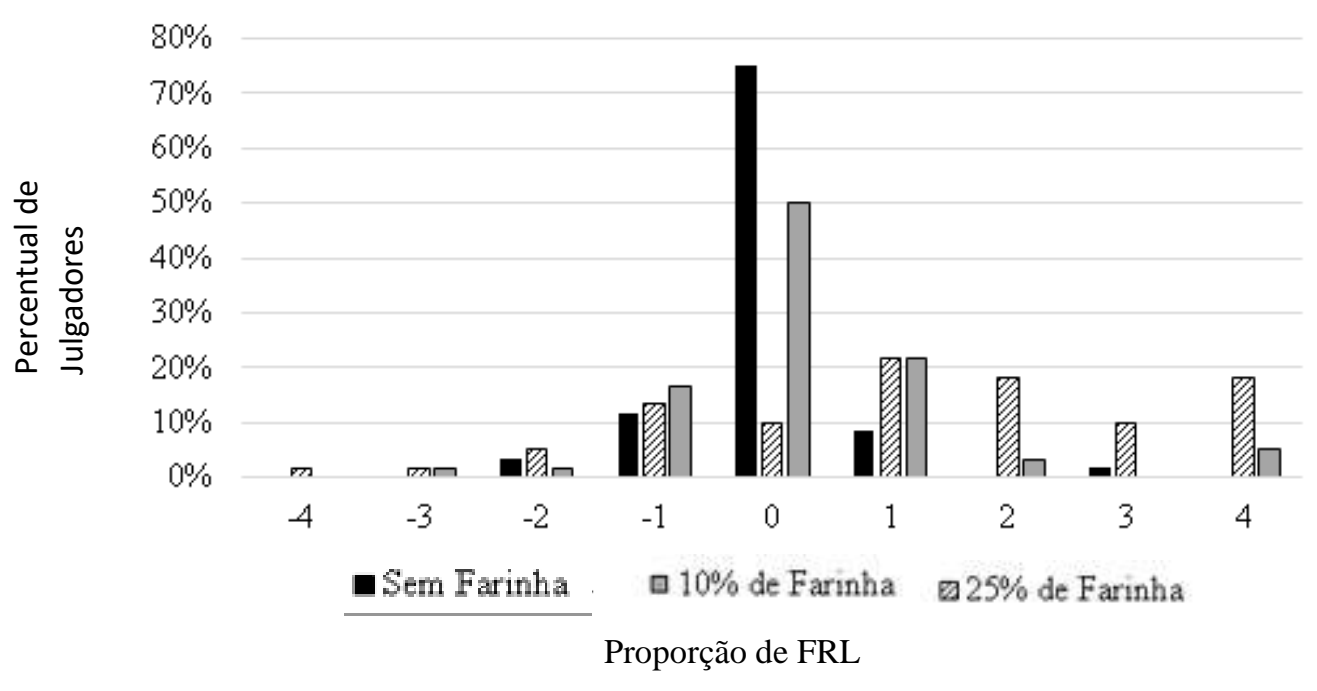

Fonte: Autores (2021).

As análises estatísticas ao avaliar a escala do ideal das três formulações, mostraram que apenas as amostras com 25\% de FRL diferiram significativamente para os parâmetros de sabor e sabor residual. A Tabela 4 destaca a mediana do resultado das análises estatísticas quanto aos parâmetros de sabor, crocância e sabor residual, para os biscoitos com gradativa substituição de farinha de resíduo de laranja. Observa-se que a crocância e sabor residual das amostras com 10\% e 0\% de FRL apresentaram medianas estatisticamente iguais a zero, isso implica que a substituição de 10\% de FRL foi bastante satisfatório. Já a mediana da amostra com 25\% diferiu do valor ideal nas três variáveis avaliadas, sendo essa a amostra menos aceita. Nas figuras 1, 2 e 3, os resultados da comparação das amostras ficam mais evidentes.

Na figura 1, percebe-se que a amostra com 10\% de FRL foi dita como ideal para metade dos provadores em relação ao sabor, embora as amostras sem farinha de resíduo ainda tenham percentual maior, a substituição da farinha é agradável ao paladar dos provadores. Em contrapartida, menos de 10\% dos avaliadores julgaram como ideal a substituição de 25\% FRL, nota-se também que, mesmo avaliada como acima do ideal não houve picos que indicassem sabor extremamente mais forte que o ideal. 
Figura 2. Escala do ideal para a crocância de acordo como tipo de biscoito.

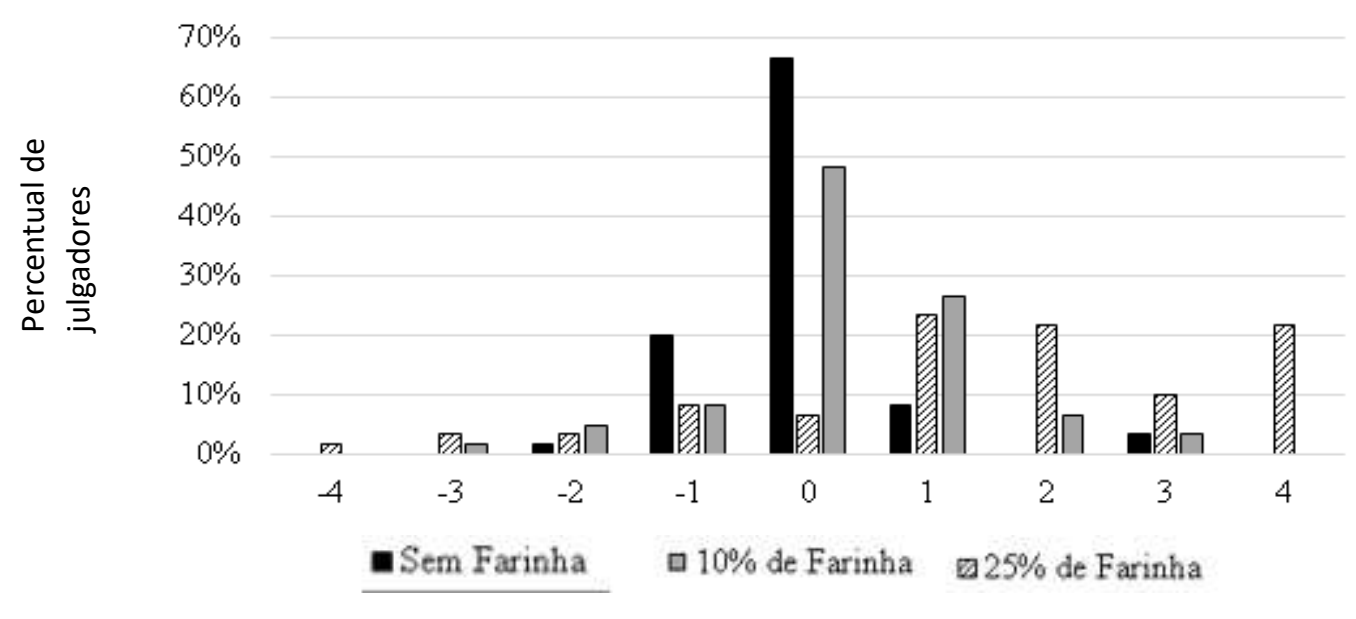

Proporção de FRL

Fonte: Autores (2021).

Bastante similar ao que foi visto na avaliação do atributo de sabor, na Figura 2 pode-se notar que amostras de biscoito tiveram avaliação semelhante, mas para a crocância dos biscoitos, embora tenha uma margem menor quando as amostras de $10 \%$ de FRL são comparadas com as amostras com $25 \%$.

Figura 3. Escala do ideal para a sabor residual de acordo como tipo de biscoito.

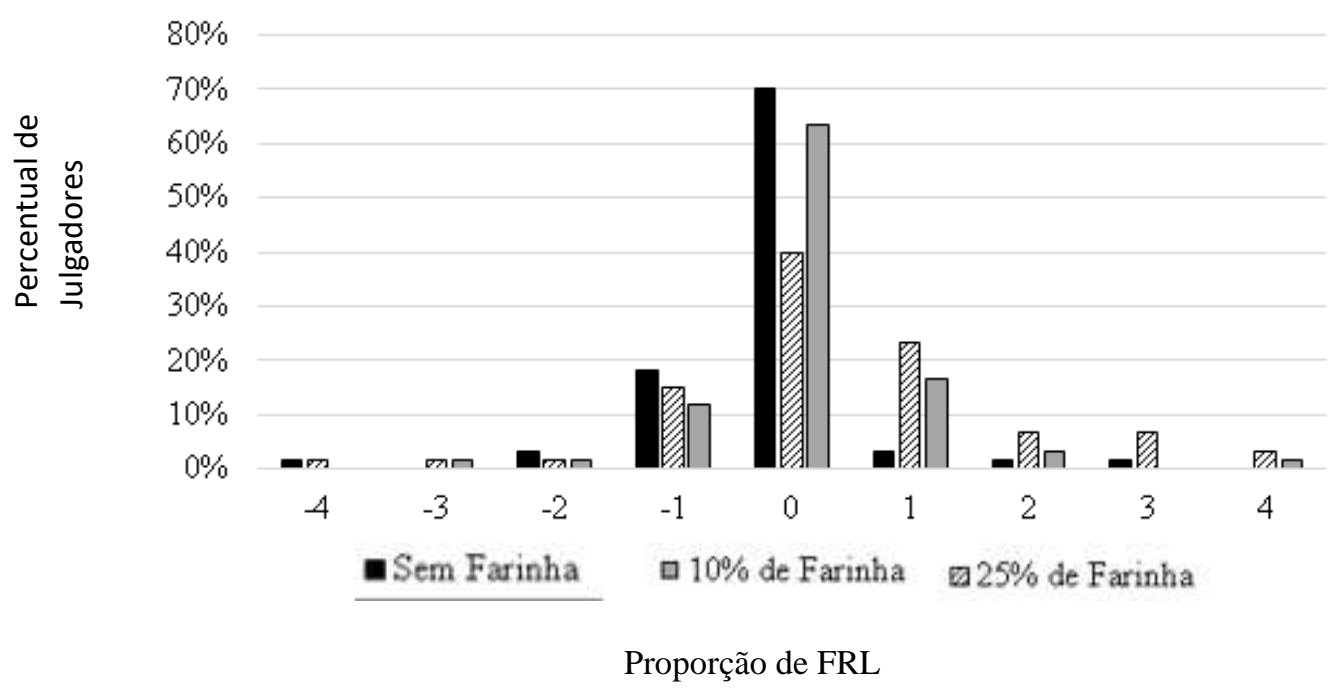

Fonte: Autores (2021).

Entretanto, no que se diz respeito ao sabor residual dos biscoitos, observa-se uma aceitação maior em relação à concentração de farinha, muito bem avaliados, os biscoitos FRL10\% se mostraram com sabor residual agradável e logo atrás com quase a metade das avaliações também na zona do ideal para a FRL25\%. Esses dados mostram que o aumento na concentração de FRL podem influenciar no sabor final do produto, como visto nas amostras de FRL25\%, mas sensorialmente agradáveis em concentrações FRL10\%. Rigo (2017) observou ao avaliar biscoitos tipo cookie adicionados de farinha de bagaço de malte (FBM) como fonte de fibra (10, 20 e 30\% de FBM) que o atributo em que metade dos participantes mais gostaram foi 
o sabor, já o atributo menos preferido pelos participantes foi o sabor residual da formulação de biscoito com $30 \%$ de farinha de bagaço de malte que foi citado por $16 \%$ dos degustadores desses biscoitos tipo cookie adicionados de farinha de bagaço de malte como fonte de fibra.

Considerando que ao se desenvolver um novo produto, um dos pontos fundamentais é avaliar sua aceitabilidade, a fim de predizer seu comportamento frente ao mercado consumidor (Moscatto et al., 2004). A substituição parcial de farinha de arroz por farinha de resíduo de laranja trouxe novas características ao produto, tendo em vista o gradiente de substituição da FRL para a produção de biscoitos com boa aceitação sensorial.

Portanto, diz-se que é possível a produção de biscoito tipo cookie com substituição parcial da farinha de arroz por farinha de resíduo de laranja, formando assim um biscoito sem glúten. Desse modo a farinha de resíduo de laranja é uma possível alternativa viável, sabendo-se que este trata-se de um resíduo não muito utilizado, para elaboração de biscoitos tipo cookie.

\section{Conclusão}

As análises físico-químicas e microbiológicas mostraram que os biscoitos atendem aos padrões da legislação, estando aptos ao consumo. A análise sensorial revelou boa aceitação sensorial dos biscoitos com substituição parcial da farinha de arroz por Farinha de Resíduo de Laranja sendo a formulação FRL10\% a mais aceita, oferecendo um valor nutricional diverso e maior que as demais farinhas utilizadas para processamento de cookies, aumentando a qualidade de vida do consumidor dessa linha de produto, visto que a ingestão desse produto conta com a inserção de fibra alimentar propriedades nutricionais presente na farinha de resíduo de laranja na alimentação de quem adere.

Desse modo, a farinha de resíduo de laranja é uma possível alternativa viável, sabendo-se que este trata-se de um resíduo não muito utilizado, para elaboração de biscoitos tipo cookie.

\section{Referências}

Anuário Da Agricultura Brasileira. (2016). Informa Economics FNP.

IBGE (2021) Instituto Brasileiro de Geografia e Estatística, Levantamento Sistemático da Produção Agrícola - LSPA.

Cayres, C. A. (2014). Transforação dos residuos de industrilização de laranja pera (citrus sinensis osbeck) em farinhas para obtenção de biscoito doce. (2014). 109 f. Dissertação (Mestrado) - Curso de Tecnologia de Processos Químicos, Universidade Federal do Rio de Janeiro.

Calleguari, F. L. et al. (2010). Desenvolvimento, aceitabilidade e intenção de compra de Cookie de frutas. 2010.Norte Científico, 5(1).

Rosolen, M. D. et al., (2018). Biscoitos tipo cookies desenvolvidos a partir de farinha de casca de laranja. Revista Destaques Acadêmicos, 10(4).

De Sá Leitão, B. R. G. \& De Sá Leitão, C. S. (2015). Sustentabilidade e elaboração de novos produtos através do aproveitamento de resíduo alimentar. Revista Científica do Ciesa, 2(2), 97.

Farias Silva, C. E., Gama, B. M. V., Oliveira, L. M. T., Araújo, L. T., Araújo, M. L., Oliveira Júnior, A. M., \& Abud, A. K. de. S. (2016). Uso da laranja lima e seus resíduos no desenvolvimento de novos produtos. Brazilian Journal of Biosystems Engineering, 10(1), 69-96.

Fasolin, L. H. et. al. Biscoitos produzidos com farinha de banana: avaliações química, física e sensorial. (2007). Ciência e Tecnologia de Alimentos, 524-529.

Bender, A. B. B., Luvielmo, M. de M., Loureiro, B. B., Speroni, C. S., Boligon, A. A., Silva, L. P., \& Penna, N. G. (2016). Obtenção e caracterização de farinha de casca de uva e sua utilização em snack extrusado. Brazilian Journal of Food Technology, 19(e2016010), 1-9.

Brasil. Ministério da Saúde. Agência Nacional de Vigilância Sanitária. (2005). Resolução RDC n. 263, 22 de setembro de 2005. Regulamento técnico para produtos de cereais, amidos, farinhas e farelos. Diário Oficial da República Federativa do Brasil, Poder Executivo.

Payret, B., Talhaoui, F., Kerckhofs, G., Brijs, K., Goesaert, H., Wevers, M. \& Delcour, J. A. ( 2009).The role of sugar and fat in sugar-snap cookies: Structural and textural properties. Journal of Food Engineering, 90(3), 400-408.

Associação Brasileira das Indústrias de Biscoitos, Massas Alimentícias e Pães \& Bolos Industrializadas (ABIMAPI). (2021). Estatística - Biscoito.

Santos, C. A., Ribeiro, R. C., Silva, E. V. C., Silva, N., \& Silva, B. A. (2011). Elaboração de biscoito de farinha de buriti (Mauritia flexuosa L. f) com e sem adição de aveia (Avena sativa L.). Revista Brasileira de Tecnologia Agroindustrial. 5(1), 262-275. 
Lima, S. C. V. C., Arrais, R. F., \& Pedrosa, L. F. C. (2004). Avaliação da dieta habitual de crianças e adolescentes com sobrepeso e obesidade. Revista de nutrição, 17(4), 469-477.

Matos, S. R. de, Gandolf, L., \& Santos, J. E. dos. (2016). Os impactos psicossociais gerados pelo diagnóstico e tratamento da doença celíaca.

Mariani, M. et al. (2015). Elaboração e avaliação de biscoitos sem glúten a partir de farelo de arroz e farinhas de arroz e de soja. Brazilian Journal of Food Technology, 18(1), 70-78.

Moraes, K. S. et al. Avaliação tecnológica de biscoitos tipo Cookie com variações nos teores de lipídio e de açúcar. 2010.Ciência e Tecnologia de Alimentos, $233-242$,

Assis, L. M. de et al., (2009). Propriedades nutricionais, tecnológicas e sensoriais de biscoitos com substituição de farinha de trigo por farinha de aveia ou farinha de arroz parboilizado. Alimentos e Nutrição Araraquara, 20(1), 15-24.

Capriles, V. D., Coelho, K. D., Matias, C. G., \& Arêas, J. A. G. (2006). Efeito da adição de amaranto na composição e na aceitabilidade do biscoito tipo cookie e do pão de forma. Alimentos e Nutrição, 17, 269-274.

O'shea, N. et al. (2015). Modelling the effects of orange pomace using response surface design for gluten-free bread baking. Food chemistry, 166, 223-230.

Apha. (2015). Compendium of Methods for the Microbiological Examination of Foods (5a ed). APHA Press.

Instituto Adolfo Lutz (São Paulo - Brasil). (2008). Métodos físico-químicos para análise de alimentos. (4a ed.), Instituto Adolfo Lutz.

Dutcosky, S. D. (2013). Análise sensorial de alimentos. (4a ed.), Champagnat. 531 p

Minim, V. P. R. (2013). Análise sensorial: estudos com consumidores. (3a ed.), Editora UFV, 332 p.

Gibbons, J. D., \& Chakraborti, S. (2010). Nonparametric Statistical Inference, (5th ed.), CRC Press.

IBM Corp. Released 2016. IBM SPSS Statistics for Windows, Version 24.0. IBM Corp.

Brasil. (2001). Resolução n ${ }^{\circ} 12$ de 02 de janeiro de 2001. Institui o Regulamento Técnico sobre os padrões microbiológicos para alimentos. Diário Oficial da União, Poder Executivo.

Zuniga, A. D. G., Coelho, A. F. S., Ferreira, E. S., Resende, E. A., \& Alameida, K. N. (2011). Avaliação da vida de prateleira de biscoito de castanha de caju tipo integral. Revista Brasileira de Produtos Agroindustriais, 13, 251-256.

Dias, B. F. et al. (2016). Caracterização fisíco-química e análise microbiológica de cookie de farinha de aveia. Journal of Neotropical Agriculture, 3, 10-14,

Komeroski, M. R. (2016). A relevância dos componentes sensoriais nas escolhas alimentares.

Moura, F. A., Spier, F., Zavarezi, E. R., Dias, A. R. G., \& Elias, M. C. (2010). Biscoitos tipo “cookie” elaborados com diferentes frações de semente de abóbora (Curcubita máxima). Alimentos e Nutrição, 21, 579-585.

Perez, P. M. P., \& Germani, R. (2007). Elaboração de biscoitos tipo salgado, com alto teor de fibra alimentar, utilizando farinha de berinjela (Solanum melongena, L.). Food Science and Technology, 27, 186-192.

Santos, A.K., Rodrigues, E., Hernandes, T., \& Oliveira, A. P. (2017). Caracterização física e química de biscoito salgado enriquecido com farinha de resíduos do processamento da cenoura e especiarias. Revista Brasileira de Tecnologia Agroindustrial.

Fennema, O. R. (2000). Química de los alimentos. (2a ed.), Acribia.

Klein, Â. L., Bresciani, L., \& De Oliveira, E. C. (2015). Características físico-químicas de biscoitos comerciais do tipo cookies adquiridos no vale do taquari. Revista Destaques Acadêmicos, 7(4).

Gomes, J. C., \& Oliveira, G. F. (2011). Análises físico-químicas de alimentos. Ed. UFV.

Erkel, A. et al. (2015). Utilização da farinha da casca de abacaxi em cookies: caracterização físico-química e aceitabilidade sensorial entre crianças. Revista Uniabeu, 8, 272-288.

Silva, I. G. da et al. (2019). Elaboração e análise sensorial de biscoito tipo cookie feito a partir da farinha do caroço de abacate. Brazilian Journal of Food Technology, 22

Rigo, M. et al. (2017). Avaliação físico-química e sensorial de biscoitos tipo cookie adicionados de farinha de bagaço de malte como fonte de fibra. Ambiência. Guarapuava (PR) 13, 47-57.

Moscatto, J. A., Prudêncio-Ferreira, S. H., \& Hauly, M. C. O. (2004) Farinha de yacon e inulina como ingredientes na formulação de bolo de chocolate. Food Science and Technology, 24, 634-640. 